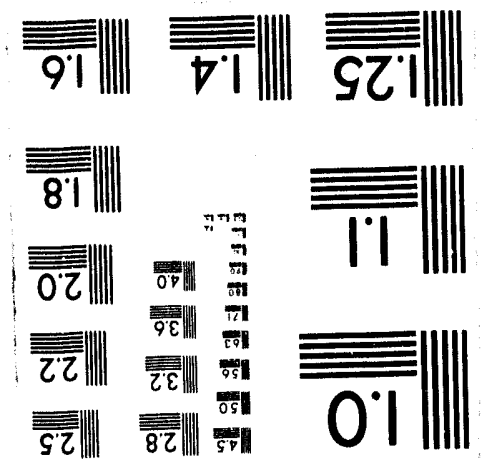



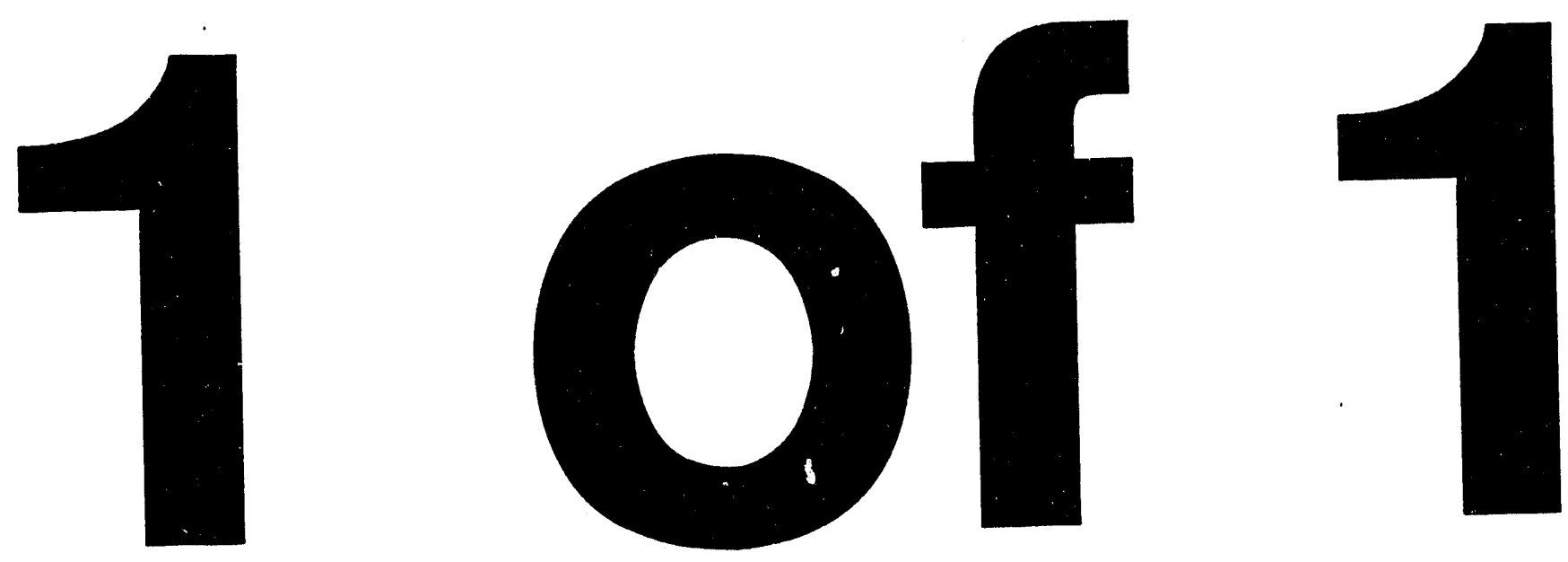


\title{
INVESTIGATION OF WETTABILITY BY NMR MICROSCOPY AND SPIN-LATTICE RELAXATION
}

\author{
By \\ Daryl A. Doughty \\ Liviu Tomutsa
}

November 1993

Work Performed Under Cooperative Agreement No. DE-FC22-83FE60149

\author{
Prepared for \\ U.S. Department of Energy \\ Assistant Secretary for Fossil Energy
}

\author{
Robert Lemmon, Project Manager \\ Bartlesville Project Office \\ P. O. Box 1398 \\ Bartlesville, OK 74005
}

\author{
Prepared by \\ IIT Research Institute \\ National Institute for Petroleum and Energy Research \\ P.O. Box 2128 \\ Bartlesville, OK 74005
}




\section{TABLE OF CONTENTS}

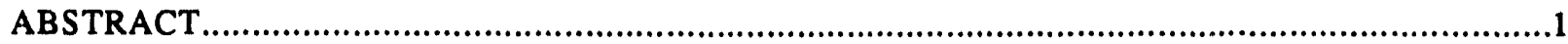

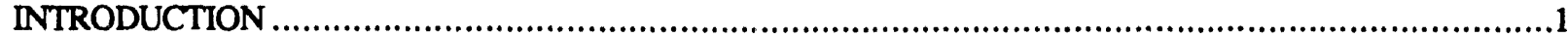

METHODOLOGY

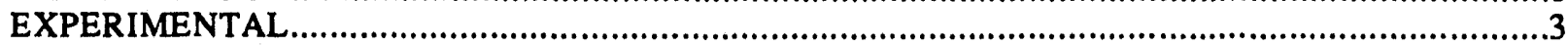

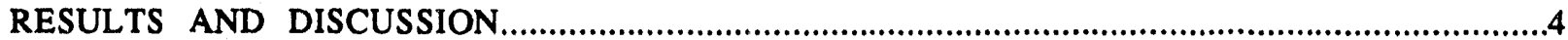

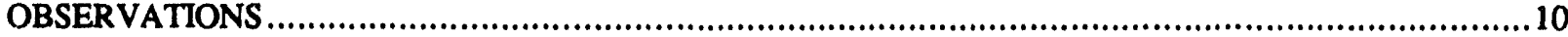

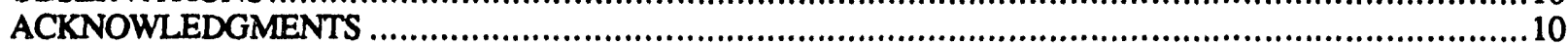

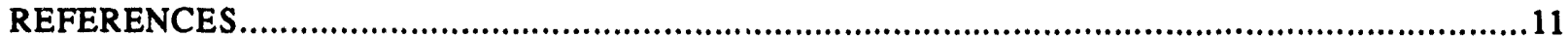

\section{TABLES}

1 Stretched exponential fit parameters fo brine in sandstone .........................................................5

2 Stretched exponential fit parameters for capillary tube bundles......................................................9

\section{ILLUSTRATIONS}

1 (a) $A$ three-dimensional object subject to a main magnetic field $B_{0}$ and a magnetic field gradient $\mathrm{G}_{T}$; ; (b) Conventional NMR spectrum in the absence of the field gradient and and for identical nuclei; (c) NMR spectrum of the object for a nonzero field gradient applied in the direction $\mathrm{G}_{\mathrm{T}, \mathrm{p}}$

2 Projection reconstruction echo pulse sequence showing timing of RF pulses, receiver

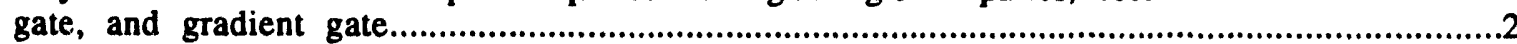

3 Surface rendering of Fontainebleau sandstone showing the thin layer of water near the rock grain surface. The rock grains and bulk water have been made transparent .....................................4

4 Plot of normalized magnetic moment $Y R(t)$ versus time in milliseconds: bulk brine; brine in Fontainebleau sandstone; brine in Cleveland sandstone; brine in Berea sandstone.

5 Surface rendering of fluid in model core $\mathrm{p}$ ig phantom with all pixels of the imaged region with intensity below 60 rendered invisible. The region shown in all four views is 1,300 microns high, 3,500 microns wide, and 7,000 microns front to back. A - Brine at initial brine saturation; B - Oil phase at residual brine after 10 - 15 PV of Soltrol; C - Oil phase at residual brine after 25 - 30 PV of Soltrol; D - Residual oil phase after 15 - 20 PV of brine.

6 Surface rendering of fluid in model core plug phantom with all pixels of the imaged region with intensity below 60 rendered invisible. The region shown in all four views is 1,300 microns high, 1,300 microns wide, and 2,600 microns front to back. A - Brine at initial brine saturation; B - Oil phase at residual brine after 10 - 15 PV of Soltrol; C - Oil phase at residual brine after 25 - 30 PV of Soltrol; D - Residual oil phase after 15 - 20 PV of brine.

7 Plot of normalized magnetic moment $\mathrm{YR}(\mathrm{t})$ versus time in milliseconds for brine and Soltrol from residual oil stage in the model core plug: brine phase; residual oil phase.

8 Plot of normalized magnetic moment $Y R(t)$ versus time in milliseconds for vertically mounted glass capillary bundle; single-phase brine; brine phase in two-phase brine/Soltrol

9 Plot of normalized magnetic moment $Y R(t)$ versus time in milliseconds for vertically mounted glass capillary bundle; single-phase Soltrol; Soltrol phase in two-phase brine/Soltrol

10 Plot of normalized magnetic moment $Y R(t)$ versus time in milliseconds for horizontally glass glass capillary bundle; single-phase brine; brine phase in two-phase brine/Soltrol; brine phase in two-phase Soltrol/brine.

11 Plot of normalized magnetic moment $Y R(t)$ versus time in milliseconds for horizontally mounted glass capillary bundle; single-phase Soltrol; Soltrol phase in two-phase Soltrol/brine; Soltrol phase in two-phase brine/Soltrol.

12 Plot of normalized magnetic moment $Y R(t)$ versus time in milliseconds for horizontally mounted Teflon capillary bundle; single-phase brine; brine phase in two-phase brine/Soltrol; brine phase in two-phase Soltrol/brine.

13 Plot of normalized magnetic moment YR( $t)$ versus time in milliseconds for horizontally mounted Teflon capillary bundle; single-phase Soltrol; Soltrol phase in two-phase Soltrol/brine; Soltrol phase in two-phase brine/Soltrol. 


\title{
INVESTIGATION OF WETTABILITY BY NMR MICROSCOPY AND SPIN-LATTICE RELAXATION
}

\author{
by Daryl A. Doughty and Liviu Tomutsa
}

\begin{abstract}
The wettability of reservoir rock has an important impact on the efficiency of oil recovery processes and the distribution of oil and water within the reservoir. One of the potentially useful tools for wettability measurements is nuclear magnetic resonance (NMR) and spin-lattice relaxation. More recently using NMR microscopy NIPER has developed the capability of imaging one- and two-phase fluid systems in reservoir rock at resolutions to 25 microns. Effects seen in the images of fluids within the pore space of rocks near the rock grain surfaces hinted at the possibility of using NMR microscopy to map the wettability variations at grain sites within the pore space. Investigations were begun using NMR microscopy and spin-lattice relaxation time measurements on rock/fluid systems and on well-defined fractional wet model systems to study these effects. Relaxation data has been modelled using the stretched exponential relationship recently introduced. Comparisons of the NMR microscopy results of the model system with the rock results indicate that the observed effects probably do not reflect actual wettability variations within the pore space. The results of the relaxation time measurements reveal that even in the simple model studied, the behavior of two phases is somewhat ambiguous and much more complex and requires more study.
\end{abstract}

\section{INTRODUCTION}

Wettability is a measure of the affinity of a solid surface for the preferential adherence of one fluid phase in the presence of other immiscible fluids. In the field of reservoir engineering where rock/oil/water systems are the objects of interest, the rock is considered to be water-wet, oil-wet, or some intermediate state. The wettability of the reservoir rock has an important impact on the efficiency of oil recovery processes and the distribution of oil and water within the reservoir. The measurement of wettability is an important part of characterizing petroleum reservoirs and designing effective secondary and tertiary recovery processes. Several reviews of this topic have recently appeared which describe the different methods of measuring wettability and evaluating its influence on oil recovery (Anderson, 1986; Cuiec, 1991).

One of the potentially useful tools for measuring wettability is NMR spectrometry and spin-lattice relaxation. The spin-lattice relaxation time $\left(T_{1}\right)$ is one of the characteristic NMR parame ers for a given fluid/rock system and is a measure of the time required for the recovery of the bulk magnetic moment of the sample along the direction of the strong magnetic field in the NMR spectrometer. It is controlled by the interaction of the molecules of the fluid with each other and the confining rock surfaces. Early investigations showed that the $T_{1}$ time for water in contact with water-wet grain surfaces was shorter than that for water in contact with oil-wet surfaces (Brown and Fath, 1956; Kumar et al., 1969). One possible criticism of the NMR method is that $T_{1}$ measurements, on well-defined water-wet and oil-wet rock/fluid systems are required to establish the range of measurements and it is difficult to precisely characterize the wettability of a complex pore system as represented by the typical reservoir rock even after accepted wettability or cleaning treatments (Anderson, 1986). More recent investigations of the relaxation properties of oil and water in model porous media and reservoir rock, including sandstones, carbonates, and chalks, have further refined the techniques and established relaxation measurements as a more viable too! for wettability characterization (Kenyon et al., 1988; Borgia et al., 1991; Roussel et al., 1992; Borgia et al., 1992; Barrufet et al., 1993).

NMR microscopy has been developed at the National Institute for Petroleum and Energy Research (NIPER) during the past few years into a useful tool for the visualization of fluid distributions within the pore spaces of reservoir rock at pore scale (Doughty and Maerefat, 1987; Doughty and Maerefat, 1988; Doughty and Maerefat, 1989; Mahmood et al., 1990; Doughty and Tomutsa, 1992; Tomutsa et al., 1992; Doughty et al., 1993). Threedimensional (3D) visualizations of one- and two-phase fluid systems in several types of sandstone rock have been obtained at resolutions to 25 microns. At these scales, some effects were seen which may represent the influence of variations in rock grain wettability within the pore space on the distribution and appearance of the fluids. Research was begun to investigate these effects and relate them to the more traditional measurements of fluid NMR relaxation properties on some well-defined model systems.

\section{METHODOLOGY}

The development of nuclear magnetic resonance (NMR) imaging from high resolution NMR spectroscopy is straightforward in concept. In NMR spectroscopy the sample is placed in a highly homogeneous magnetic field. All NMR-active nuclei of a given species, for example protons in water, will experience the same magnetic field and resonate at the same frequency, resulting in a sharp peak for water in the NMR spectrum, but no information is obtained to spatially differeniate one water molecule from another. If a linear gradient in magnetic field intensity is superimposed on the homogeneous field, then water protons on the side of the sample exposed to the 
lower fields will resonate at lower frequencies and so forth. What will be observed in the NMR spectrum will be a projection of the summed intensity from water protons in perpendicular planes at each position along the diameter of the sample in the direction of the gradient field from lowest to highest frequency. Figure 1 illustrates this projection process. By changing the orientation of the gradient in $3 D$ space in a regular manner, using the spherical coordinates theta and phi, information about the location of all water protons in the sample can be obtained, and an "image" of the water distribution in selected planes from the sample can be displayed.

The 3D projection-reconstruction NMRI method does not require a rapid gradient response as the gradients are turned on and a short RF pulse having a broad bandwidth irradiates the sample in the presence of the gradient which is then turned off after the signal is acquired. The advantage is that the NMR signal can be acquired immediately after the RF pulse (about $5 \mu \mathrm{sec}$ ) or after a short echo period $(1-2 \mathrm{msec})$ so that a strong signal is available. The disadvantages are that the entire sample is iradiated at once, generating very large data files and requiring longer sampling times and larger data processing periods, and a short powerful RF pulse is required to adequately excite the entire sample in the presence of the strong gradient if an echo sequence is used. The timing of the projection reconstruction echo pulse sequence is shown in Fig. 2 where the various gate signals for activating the $R F$, the gradient components, and the receiver are plotted versus time.

The spin-lattice relaxation times were measured using the inversion recovery pulse sequence. In this process, the sample is placed in the NMR spectrometer, and the

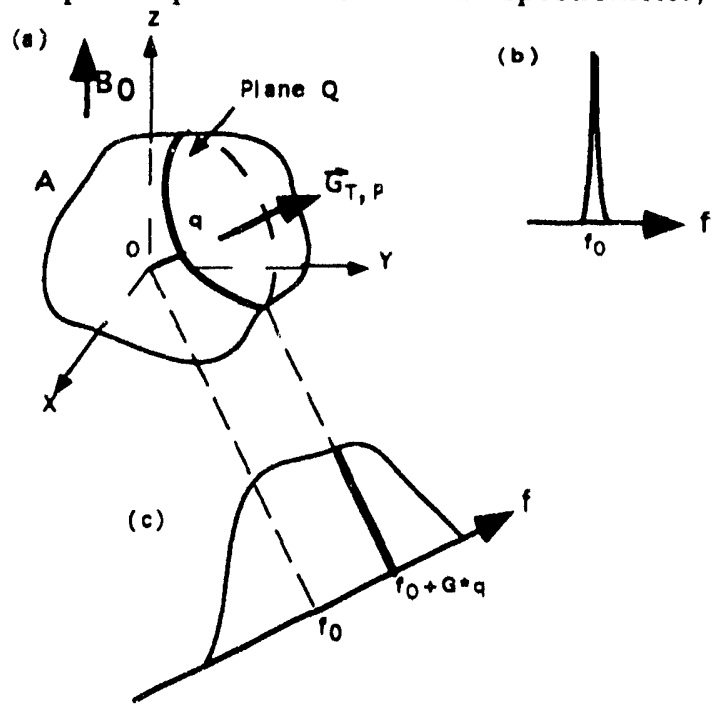

Fig 1 (a) A three-dimensional object subject to a main magnetic field $\mathbf{B}_{0}$ and a magnetic field gradient $\mathbf{G}_{\mathrm{T}, \mathrm{P}}$; (b) Conventional NMR spectrum in the absence of the field gradient and for identical nuclei; (c) NMR spectrum of the object for a nonzero field gradient applied in the direction G.. P. equilibrium bulk magnetic moment for the sample established by the spectrometer's strong magnetic field is inverted by a $180^{\circ}$ radio-frequency (RF) pulse from the sample probe RF coil. After a variable delay of $2-30,000$ milliseconds, a $90^{\circ}$ RF pulse is used to sample the bulk magnetic moment as it "relaxes" back to its equilibrium state. By making a series of measurements as the delay time is increased in a regular manner, the time evolution of the bulk magnetic moment can be obtained from which the $T_{1}$ time for the sample can be extracted. The relationship between the bulk magnetic moment, $M$, and time is

$$
M(t)=M_{0} e^{-\left(t / T_{1}\right)}
$$

where $M(t)$ is the magnetic moment at time $t$ after the $180^{\circ}$ RF pulse and $\mathrm{M}_{0}$ is the equilibrium magnetic moment. Because the inversion recovery sequence inverts the magnetic moment the actual relationship used to analyze the data is

$Y R(t)=\left(M_{\infty}-I R(t)\right) /\left(M_{\infty}-I R(0)+\Delta\right)=e^{-\left(t / T_{1}\right)}$

where $Y R(t)$ is the normalized magnetic moment, $\operatorname{IR}(t)$ is the measured NMR peak amplitude at time $t, \operatorname{IR}(0)$ is the peak amplitude extrapolated to zero delay time, $M_{\infty}$ is the peak amplitude extrapolated to long delay time and represents the equilibrium magnetic moment, and $\Delta$ is a zero-offset term that adjusts for the lack of perfect symmetry in the inversion process. $\Delta$ is typically around 50 - 100 compared to a $M_{\infty}$ of $5,000-16,000$ (Kenyon et al., 1988).

Bulk fluids are generally characterized by a single relaxation time so a plot of the normalized magnetic moment versus time is linear on a semi-log plot. Because the relaxation rate is affected by the interaction of the fluid with the pore walls, the pore volume-w-surface ratio (V/S) impacts the relaxation rate. Porous rock typically has a distribution of pore sizes leading to a distribution of V/S values and a superposition of relaxation rates for the various pore sizes resulting in a nonlinear semi-log plot of
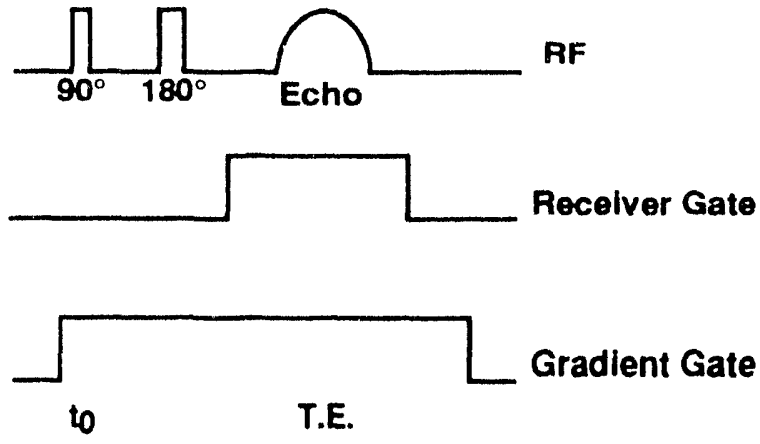

Fig 2 Projection reconstruction echo pulse sequence showing timing of RF pulses, receiver gate, and gradient gate. 
YR( $t)$. These cases have been analyzed using two- or threeexponential summations and two or three values of $T_{1}$ for the different pore size ranges. Recently, the concept of the stretched exponential relationship was developed and given by

$$
Y R(t)=e^{-\left(t / T_{1 S}\right)^{\alpha}}
$$

where $T_{1 s}$ is the "stretched" relaxation time and $\alpha$ is related to the distribution of relaxation rates (Kenyon et al., 1988). If the distribution of relaxation rates is Gaussian, then $\alpha=$ $2 / 3$.

\section{EXPERIMENTAL}

Sample preparation for NMR microscopy experiments on rock samples involves cutting small core plugs from a clean rock sample using miniature diamond core drills to obtain plugs with a diameter of $5.3 \mathrm{~mm}$ and a length of 7.8 $\mathrm{mm}$. This was done with a sample of Fontainebleau sandstone. The core plug was mounted in a Teflon holder made from Teflon endcaps machined to the diameter of the core plug and drilled to accept 1/16-inch diameter Teflon tubing for fluid access while the sample is in the sample probe mounted in the spectrometer. The core plug and endcaps are held together snugly by using a two-layer Teflon shrink tubing system: the inner layer is FEP Teflon which shrinks at a temperature of $207^{\circ} \mathrm{C}$ and the outer layer is PTFE Teflon which shrinks at $320^{\circ} \mathrm{C}$. As the outer layer shrinks, the inner layer softens and flows tightly around the endcaps and core plug forming a leakproof system containing no protons to inferfere with the signal from the fluid system. The core plug/holder assembly was then evacuated and flushed several times with $\mathrm{CO}_{2}$ gas and then saturated under vacuum with the $\mathrm{NaCl}$ brine solution (typically $0.5 \% \mathrm{NaCl}$ by weight with $0.023 \% \mathrm{MnCl}_{2}$ added to increase the relaxation rate of the protons in the brine.)

The core plug was mounted in the horizontal coil RF probe with the small bore Teflon tubing pulled out the top for access while mounted in the spectrometer. Preliminary measurements are made to determine the $90^{\circ}$ and $180^{\circ}$ nulse lengths, the natural linewidth of the fluid in the rock, and an estimate of the $T_{1}$ value using the inversion recovery signal null method. The typical imaging experiment involves using $256 \mathrm{X}$ - and $\mathrm{Y}$-gradient components with $128 \mathrm{Z}$-gradient components, which are controlled by the acquisition computer and triggered by a gradient gate signal from the NMR spectrometer/pulse sequence. The raw image dataare collected by a high-speed analog-to-digital converter and stored by the acquisition computer. Signal acquisition parameters typically involve collecting a 256 . point digitized signal from the spectrometer at a frequency bandwidth of $200,000 \mathrm{~Hz}$. If four signals are averaged at each gradient value, the imaging experiment will last 17 hours and result in a 16 Mbyte data file. For two-phase oil and water systems, Soltrol oil adjusted to a viscosity of 5 cps is used as the oil phase. To image the oil phase separately in the presence of brine, the echo time in the imaging pulse sequence is increased to about 15 milliseconds, by which time the signal from the brine has disappeared because of more rapid signal decay caused by the $\mathrm{MnCl}_{2}$. The data file is transferred to a second computer containing a fast coprocesser board running the reconstruction software. The typical output will be a $180 \times 256 \times 256$-pixel image file where each pixel is represented by a 1-byte value giving 256 grey levels. Total processing time is about 13 hours and the image file will be about 12 Mbyte in size.

For the model systems, phantoms were made using microbore glass capillary tubing, about 650 microns $O D$ and 190 microns ID, and/or Teflon "spaghetti" tubing, about 800 microns OD and 350 microns ID. The glass capillary tubing was cleaned in hot chromic acid cleaning solution and rinsed in distilled water and dried under vacuum. One model phantom was constructed using short $10 \mathrm{~mm}$ lengths of both tubing types randomly mixed and fitted with Teflon endcaps and sealed in the two-layer Teflon shrink tubing to model a fractional-wet core plug about $4.8 \mathrm{~mm}$ in diameter. The other phantoms consisted of $30-32 \mathrm{~mm}$ lengths of the glass or Teflon capillary tubing bundled into FEP Teflon shrink tubing about 4.6 $\mathrm{mm}$ diameter. Two each of these phantoms were made. All of the above phantoms were cleaned in hot chromic acid cleaning solution to remove fingerprints, rinsed in distilled water, and dried under vacuum. The phantom core plug was saturated under vacuum with the $\mathrm{NaCl} / \mathrm{MnCl}_{2}$ brine and mounted in the horizontal coil RF probe for imaging. Two image data sets were made using the gradient sequence mentioned above but with the last one adjusted so that the two sets could be interleaved to create one larger data set with $256 \mathrm{Z}$-gradient components. Because the natural linewidth of the NMR signal for brine in the phantom was much narrower than that for brine in sandstone, a narrower frequency bandwidth of $50,000 \mathrm{~Hz}$ could be used with weaker gradient currents to achieve adequate resolution. Two additional image sets were obtained after flooding the phantom core plug in two stages with two 1.0-milliliter volumes of Soltrol oil representing about 20 - 25 total pore volumes (PV). A final image set was obtained after flooding the phantom core plug with 1.5 milliliters of the brine solution.

For the relaxation time measurements one each of the glass or Teflon capillary phantoms were saturated under vacuum with $\mathrm{NaCl}$ brine without $\mathrm{MnCl}_{2}$, and the other pair were saturated under vacuum with the Soltrol. Small corks were used at the ends of the phantoms to keep the fluid contents from leaking. The phantoms were typically measured in the horizontal coil RF probe, but the glass capillary phantoms were also measured while mounted vertically in the standard NMR sample probe. The relaxation time experiments typically involved averaging several scans for 50 values of the delay time. Relaxation measurements were also made after about 1 milliliter of the other fluid was pulled into each phantom (about 1 - 2 PV) 
to obtain measurements on two-phase systems. Relaxation time measurements were also made on the final stage of the phantom core plug saturation with the core plug in the horizontal coil probe. A relaxation time measurement was also made on the bulk brine held in a 6-mm Teflon tube mounted in the horizontal coil RF probe. Additionally, small core plugs of Fontainebleau, Cleveland, and Berea sandstone about $8 \mathrm{~mm}$ diameter and $20 \mathrm{~mm}$ long were cut, and saturated under vacuum with $0.5 \% \mathrm{NaCl}$ brine (no $\mathrm{MnCl}_{2}$ ). Relaxation time measurements were made on the three sandstone plugs and bulk brine in a glass NMR tube using the standard NMR probe.

\section{RESULTS AND DISCUSSION}

NMR imaging experiments begun on the core plug of Fontainebleau sandstone saturated with brine revealed the natural line width of the water NMR signal from the brine in the rock was $750 \mathrm{~Hz}$. This compares to the value of 800-900 Hz obtained for brine in Bentheim sandstone. A narrower line width was anticipated for the Fontainebleau sandstone because its white color would indicate a much lower content of iron which is known to cause broadening in other sandstones. The image obtained had a resolution of 30 microns per pixel. Slice images from the 3D image data set for the Fontainbleau sandstone revealed the presence of randomly scattered large pores with litule porosity in between. Petrographic image analyzsis (PIA) rneasurements on a thin-section of the sandstone showed an average porosity of $12 \%$. A recently obtained upgrade of the DICER image analysis software has the capability for surface rendering of $3 D$ volumes. Figure 3 shows a surface rendering of an isolated large pore from the above data set.
The lower intensities corresponding to rock grains and the higher intensities corresponding to bulk water have been made transparent so only the thin layer of water near the rock grain surface is visible. The irregular shape of the pore volume determined by the surrounding rock grains is apparent, as are several narrow pore throats connecting to other pores outside the volume shown. The thickness of this layer seems to change in certain spots around the pore volume which may be related to the grain surface wettability. Speculation is that in areas where the fluid in the pore does not wet the surface the transition from surface to bulk relaxation characteristics should be more abrupt leading to a thiner transition layer.

Figure 4 shows the relaxation data for water in the three sandstones together with the bulk brine. The bulk brine data are from both the standard probe and horizontal coil probe experiments. The fitted curves are those obtained using the stretched exponential relationship. The water in the Berea sandstone showed the fastest relaxation rate as exhibited by the steeper slope for the curve, followed closely by water in Cleveland sandstone, then Fontainebleau sandstone. The bulk water apparently has essentially a single relaxation rate as revealed by the straight line in the semi-log plot. The data for the three sandstones show a multicomponent relaxation process involving faster rates from fluid near the surface of the rock grains in smaller pores to slower rates for bulk fluid in the centers of the larger pores. The parameters obtained from fitting the relaxation data for the fluids in the sandstone plus that of the bulk brine using the stretched exponential relationship are shown in Table 1.

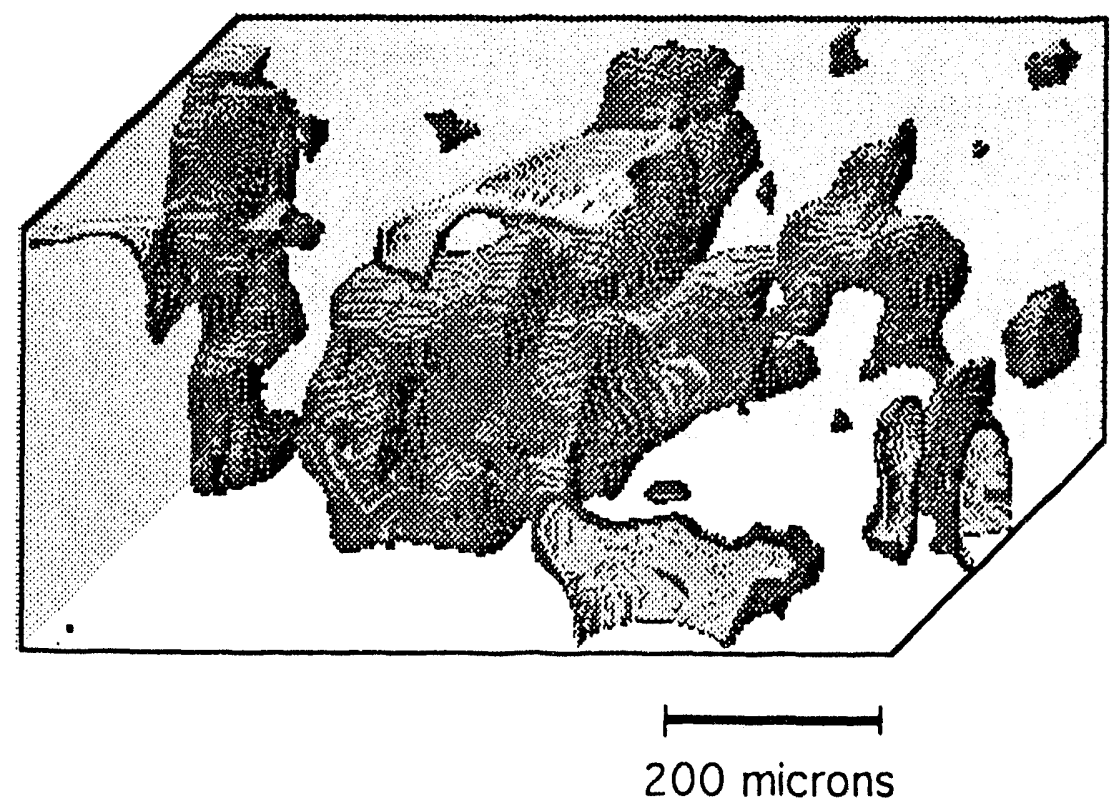

Fig 3 Surface rendering of Fontainebleau sandstone showing the thin layer of water near the rock grain surface. The rock grains and bulk water have been made transparent. 


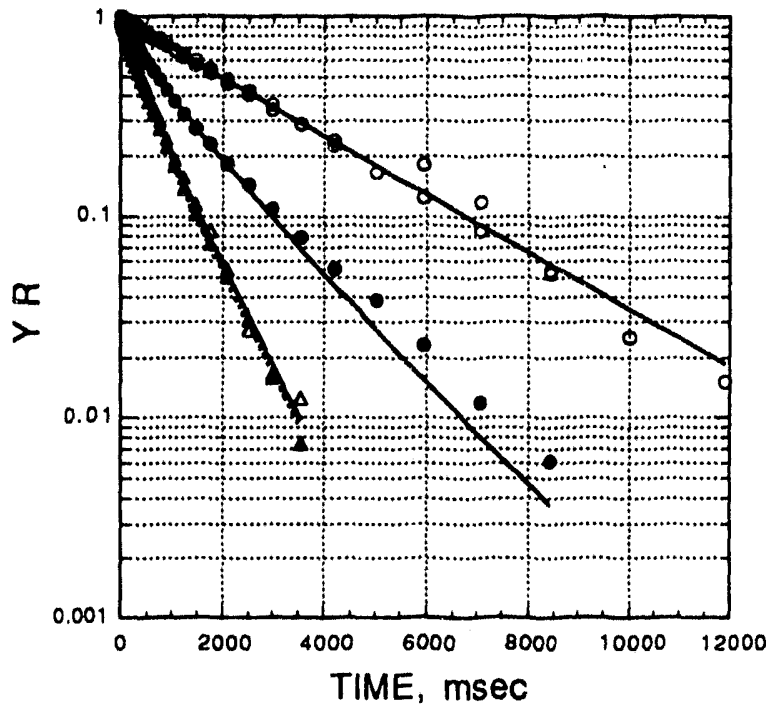

Fig 4 Plot of normalized magnetic moment $Y R(t)$ versus time in milliseconds: - bulk brine; brine in Fontainebleau sandstone; brine in Cleveland sandstone; ........ brine in Berea sandstone.

The $\alpha$ parameter for bulk brine is near 1.0 which would be the case for a single relaxation rate which exists for bulk fluids or fluids in pore systems characterized by a single V/S ratio such as some chalks (Borgia, et al., 1992). The $\alpha$ parameter for the three brine/sandstone systems are significantly smaller than 1.0 but no where near the $2 / 3$ value anticipated for the Gaussian distribution vi pore sizes or reported for the same or similar sandstones for measurements made at $10 \mathrm{MHz}$ instead of the $270 \mathrm{MHz}$ frequency of our NMR instrument (Kenyon et al., 1988).

The results of the NMR microscopy experiments on the glass/Teflon, fractional-wet model core plug are shown in Figs. 5 and 6 . Figure 5 shows four views of a horizontal block from the 3D image data set for the core plug, one for each of the fluid systems described in the experimental section. The block is 60 pixels high, 165

Table 1

Stretched exponential fit parameters for brine in sandstone

\begin{tabular}{lll} 
Sa m ple & $\alpha$ & $\mathrm{T}_{1 \varepsilon}$, seconds \\
\hline Bulk brine & 0.970 & 2.859 \\
Fontainebleau / brine & 0.851 & 1.112 \\
Cleveland / brine & 0.858 & 0.596 \\
Berea / brine & 0.822 & 0.538 \\
\hline
\end{tabular}

pixels wide, and 165 pixels front to back which represents essentially the full length of the model core plug. The data set was compressed by a factor of two to image the full length of the model compared to its diameter. The direction of fluid flow in the model was from back to front in the figure. Figure 5a shows the initial brine-saturated state where the pixel intensity below grey level 60 was made transparent to eliminate the noise and tubes. This threshold is the apparent middle of the intensity range from 30 - 90 representing the interface between the tubes and the bulk fluid in the void spaces. Each pixel represents a volume element approximately $21 \times 21 \times 42$ microns at this resolutio: in rendering the image the DICER software uses a linear interpolation between neighboring pixels so the enlaryed images do not show the individual pixels. In Fig. 5a, the brine has completely filled all void spaces between tubes and in the center of the tubes. The texture of the rendered surfaces is rough and there are some apparent image defects distorting the cylindrical shape of some of the tube centers. The glass tubes and the Teflon tubes can be distinguished by the difference in their ID's, with the Teflon tubes being larger. Teflon surfaces are strongly oil-wet while the cleaned glass surfaces should be water-wet. Figure $6 \mathrm{a}$ is an enlarged view of a block 60 pixels on edge from the center of the block shown in 5a. The rough texture of the rendered surface and the apparent image defects are more clearly shown in this view. The data set used to obtain this image was made up from two separate sets obtained consecutively and interleaved as described earlier. An image made from the first set only did not show some of the distortions apparent here. There does not appear to be any noticeable difference in the surface texture for brine in contact with glass or Teflon. Also, if the bulk brine in the center of the voids is rendered transparent to leave only the interface layer visible as for the image in Fig. 3, there are apparent thiner regions where no change in wettability of the adjacent surface should be present.

Figures $5 \mathrm{~b}$ and $6 \mathrm{~b}$ are the same respective regions as shown in $5 \mathrm{a}$ and $6 \mathrm{a}$ but show only the oil phase for the second stage fluid system where 10 - 15 PV of Soltrol oil were injected into the model core plug. NMR peak integral measurements showed that the brine/Soltrol saturations were $54 \% / 46 \%$. The brine signal was suppressed by using a longer echo time. The same intensity threshold was used to display the fluid phase as in 5a and 6a. Comparing Fig. $5 \mathrm{~b}$ to $5 \mathrm{a}$, the oil phase has preferentially occupied the voids where Teflon is the predominant surface. The only exception is the Teflon tube center visible in the lower right side of 5a. The fluid flow rate during fluid changes was controlled by adjusting the elevation of the inlet and outlet reservoirs and a pressure head of about 15 centimeters of brine or oil was used, which represents a pressure of about $0.25 \mathrm{psi}$. This means that capillary forces dominate the system. The texture of the rendered surface for the oil image is much smoother and many of the distortions noticed in 5a and 6a are not evident. Also, comparing the Teflon tube centers in Figs. $6 \mathrm{a}$ and $6 \mathrm{~b}$, the oil image appears slightly larger as if the oil more 


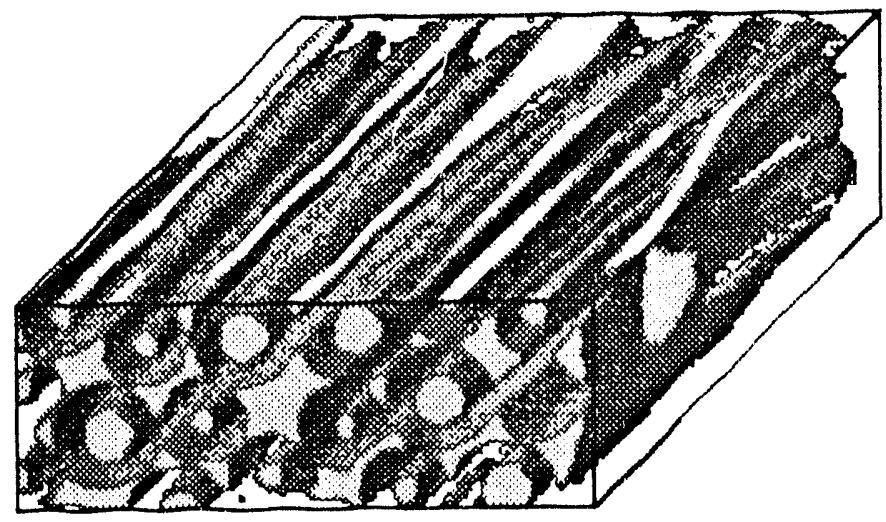

A

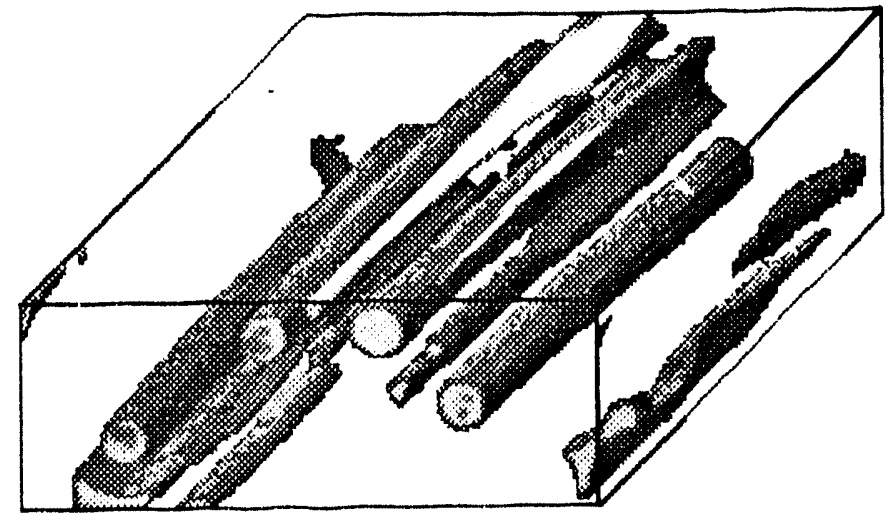

B
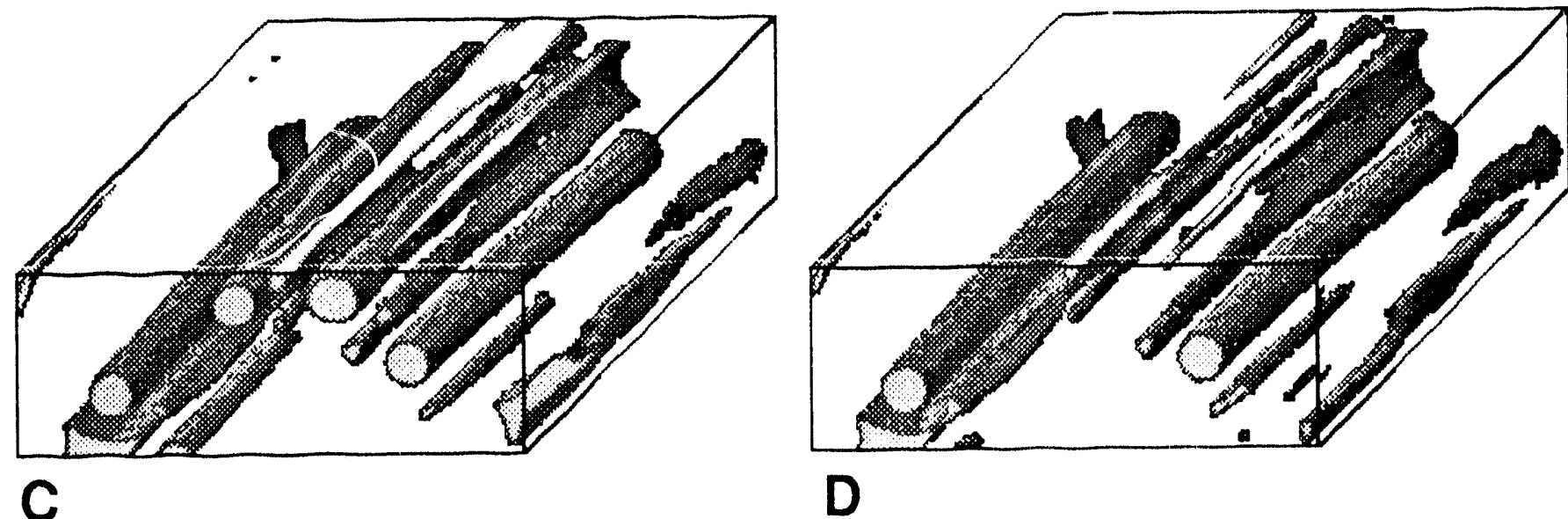

C

Fig 5 Surface rendering of nuid in model core plug phantom with all pixels of the imaged region with intensity below 60 rendered invisible. The region shown in all four views is 1300 microns high, 3500 microns wide, and 7000 mictons front to back. A - Brine at initial brine saturation; B . Oil phase at residual brine after $10-15 \mathrm{PV}$ of Soltrol; C - Oil phase at residual brine after $25-30 \mathrm{PV}$ of Soltrol; D. Residual oil phase after 15-20 PV of brine.

completely fills the tube. This appears to be true for the other oil-filled voids. There has also been an apparent shift in image position of about 4 - 5 pixels to the right and 1 2 pixels down for the oil phase image compared to the brine image. The peak position of water in the NMR spectrum is about $1,000 \mathrm{~Hz}$ from that of Soltrol oil. Considering the $50,000 \mathrm{~Hz}$ bandwidth used for imaging the model corc plug, that represents 1 part in 50 or approximately 5 pixels out of 256 used to display the image. However, the NMR frequency setting was adjusted to center the respective fluid peak when inaging that fluid so the effects of the "chemical shift effect" should have been eliminated by the procedure. No other ready explanation for these effects is available.

Figures $5 c$ and $6 c$ show the same respective regions as above but for the oil phase for the third stage fluid system where $10-15$ additional PV of Soltrol were injected into the model core plug. The measured brine/Soltrol saturations were $50.3 \% / 49.7 \%$. There are just a few additional voids which have more oil in them compared to the previous stage. The images look very similar to those of Figs. $5 b$ and $6 b$ in the surface texture and appearance.

Figures $5 \mathrm{~d}$ and $6 \mathrm{~d}$ show the same respective regions as above but for the oil phase for the fourth stage fluid system where 15-20 PV of brine were injected into the model core plug to model a residual oil system. The measured brine/Soltrol saturations were $66.3 \% / 33.7 \%$. Figure 5d shows that the two Teflon tubes near the center of the block had the oil phase replaced by brine. There are a few other areas where the oil was displaced or shifted in position. These two central Teflon tubes were near the injection port so the flow rate may have been higher in this region, accounting for the displacement of the oil despite the capillary forces. In the enlarged view of Fig. 6d, the oil phase is trapped between the outer perimeters of the two 

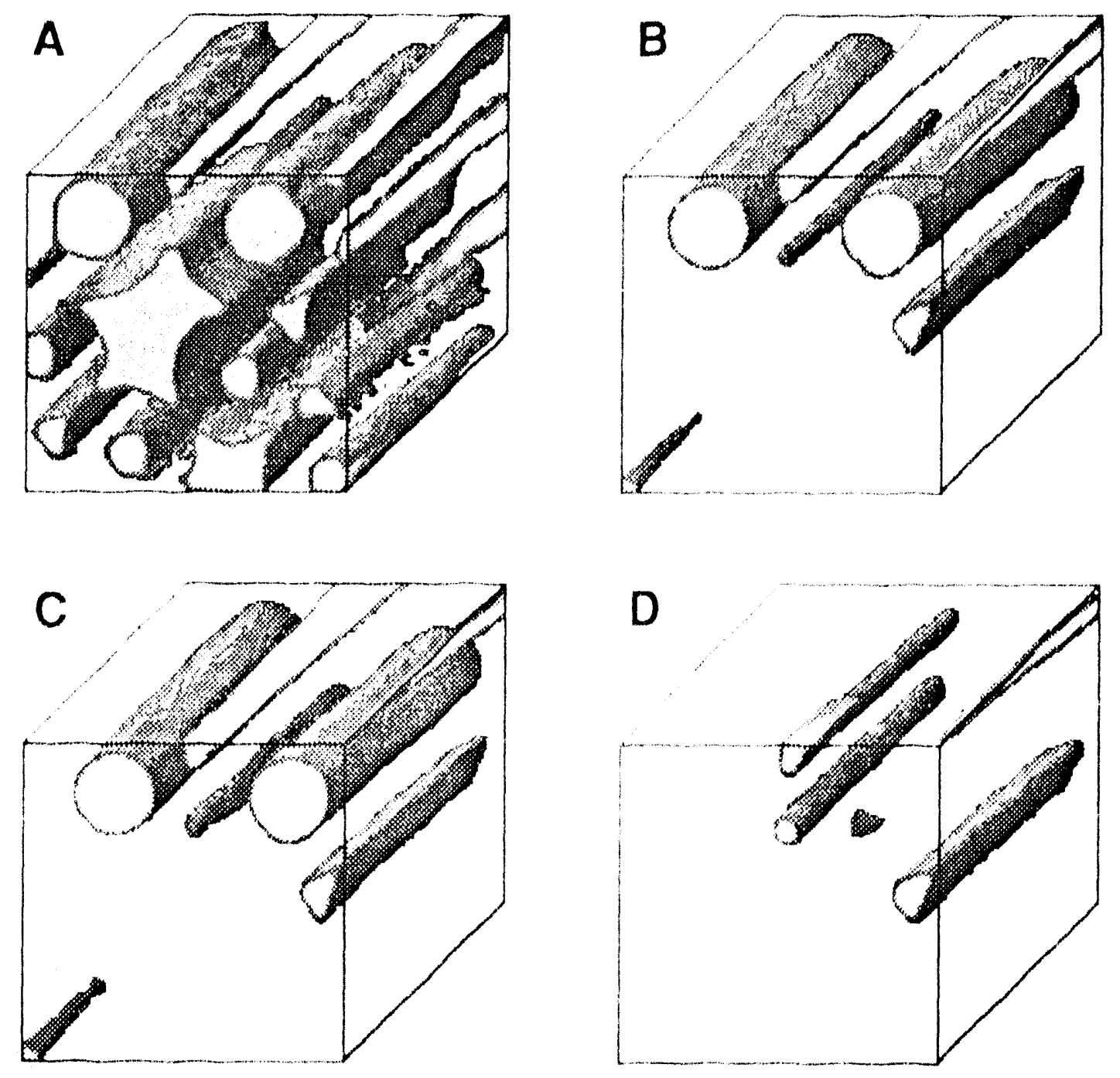

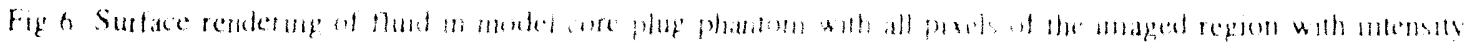

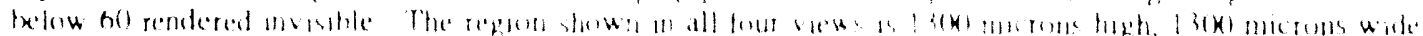

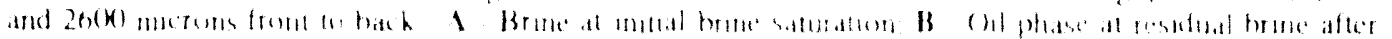

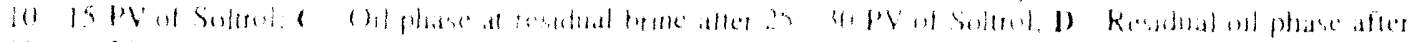
$15311 \mathrm{pul} \mathrm{hunc}$

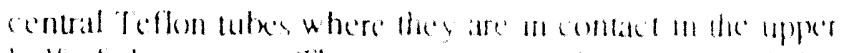

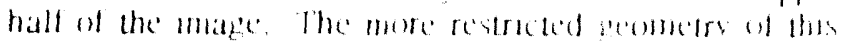

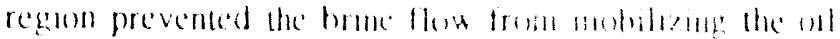

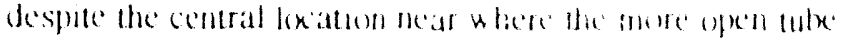
conters were flushed. All effort was make he keave a small

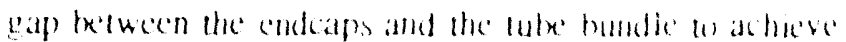

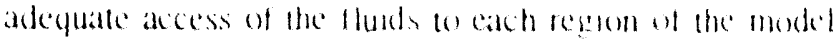

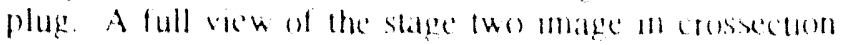
showed that onl managed be reach all regenoms of the core plug.

Figure 7 shous the results of a span lattice relaxation tume measurement on the fourth stage flud system in the model core plug. Here the normalized magnete moment for the brine and Soltrol peaks are plotled on a logeridume scale versus inverson recovery delay ume in milliseconds. The filted curves were ohlamed using the stretched

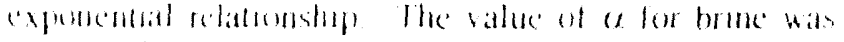

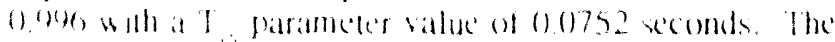

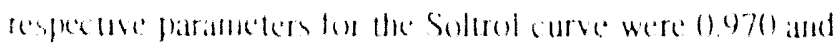

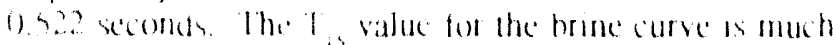
sherter than that lested on Table 1 because of the presence (1) the Mncl, an the solution. The a value is nearly le moplyuge lle model core plug has a unilorm V/S ralum III lls "pore" system. Also, the rapid relaxateon rate mas suppress some of the factors affecting 2 . The a value for

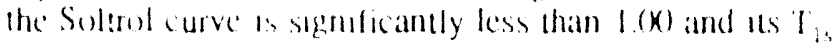
value is typical for Solterol in these eyes of systems. The nonlmear value of a magh reflect the more nonumiform

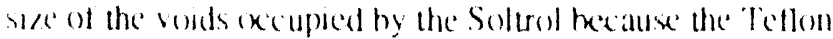
whe centers are segnificantly larger than the glass capillaries excupted by the brone. 


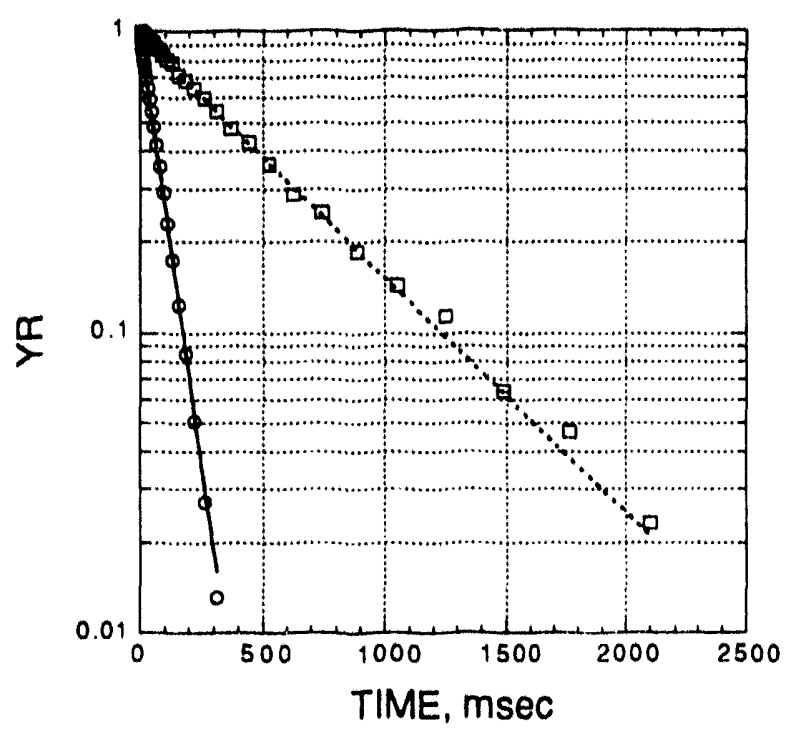

Fig 7 Plot of normalized magnetic moment $Y R(t)$ versus time in milliseconds for brine and Soltrol from residual oil stage in the model core plug: - brine phase; $\cdots \boxminus \cdots$ residual oil phase.

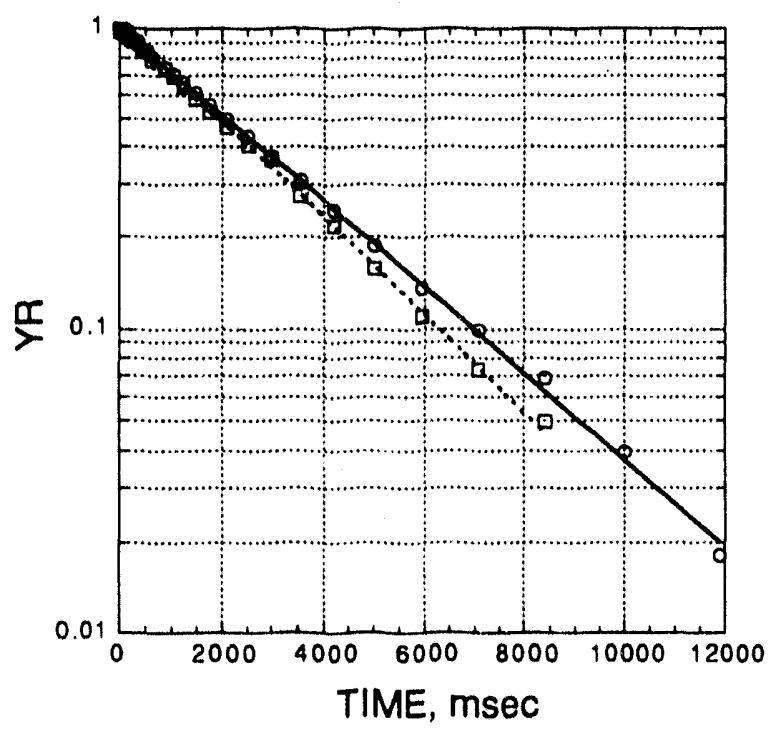

Fig 8 Plot of normalized magnetic moment YR(t) versus time in milliseconds for verticallty mounted glass capillary bundle; - single-phase brine; ... - ... brine phase in twophase brine/Soltrol.

The results of the relaxation time experiments on the four glass or Teflon capillary bundles are shown in Figures $8-13$ and the stretched exponential fitted parameters are given in Table 2. Figure 8 shows the relaxation data for the brine in the glass capillary bundle mounted vertically parallel to the magnetic field and for the brine phase in the same phantom with Soltrol oil injected on top the brine (brine is wetting phase). Figure 9 shows the relaxation data for the Soltrol in the glass capillary bundle vertically mounted with the oil as the only phase

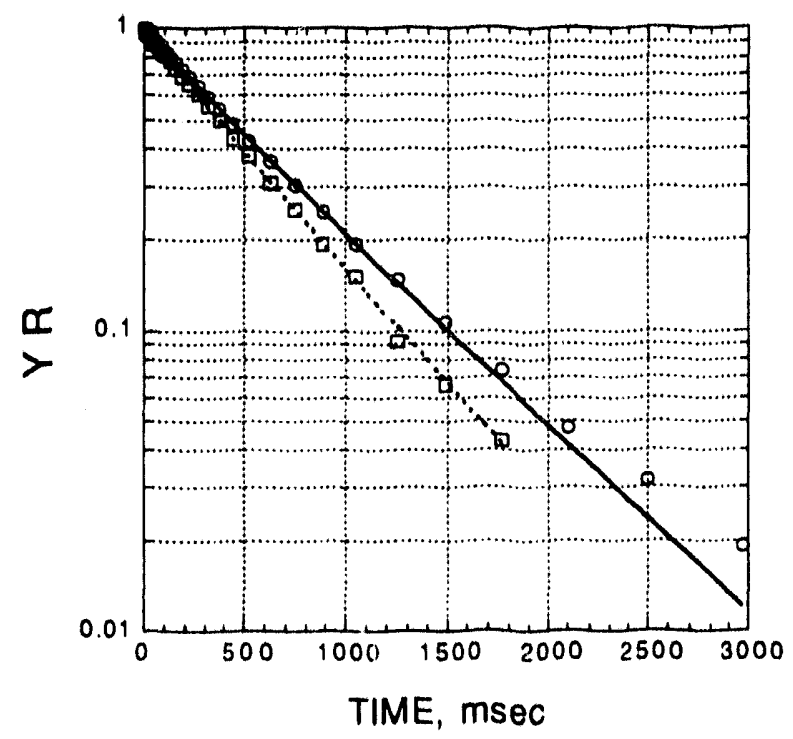

Fig 9 Plot of normalized magnetic moment $Y R(t)$ versus time in milliseconds for verticallty mounted glass capillary bundle; - single-phase Soltrol; … - ... Soltrol phase in twophase brine/Soltrol.

and also the Soltrol phase from the previous two-phase system (brine is wetting phase). The natural line widths of the fluids in these two systems were very narrow $4 \mathrm{~Hz}$ for the brine and $20 \mathrm{~Hz}$ for the Soltrol) compared to those see 1 in the model core plug system discussed previously (both fluids had linewidths around $160-200 \mathrm{~Hz}$ ). The line width for the brine in the model core plug would be enhanced by the presence of the $\mathrm{MnCl}_{2}$. The results show that the single phase fluid in each case had a longer relaxation time than the corresponding fluid in the two-phase system. This is revealed by the more gentle slope of the curve and the higher value for $T_{1 s}$ shown in Table 2. Also, as revealed by the $\alpha$ value of for the two fluids, the brine data were essentially linear in the semi-log plot (near 1.00) while the Soltrol data were significantly nonlinear $(\alpha=0.964$ or 0.951 ).

When the same glass capillary bundles were tnounted in the horizontal position with the magnetic field perpendicular to the axis of the bundle, the data show significant differences. Figures 10 and 11 show the relaxation data for the one- and two-phase fluid systems with the fitted surves. The stretched exponential fit parameters are given in Table 2 . Figure 10 shows the brine phase results. In each case, the fluid listed first in the legend was the first phase injected into the dry phantom. The natural line widths of the two fluids were much broader in the horizontal position with that for the brine equal to $120 \mathrm{~Hz}$ and that for the oil equal to $230 \mathrm{~Hz}$. These values are near the results for the model core plug which was also mounted horizontally. The most important parameter of the systern affecting line width is the local magnetic field 
Table 2

Stretched exponential fit parameters for capillary tube bundles

\begin{tabular}{|c|c|c|c|c|}
\hline Sample & $\alpha$, Brine & $T_{1 s}$, Brine, sec & $\alpha$, Soltrol & $T_{18}$, Soltrol, sec \\
\hline $\begin{array}{l}\text { GICp/Brine } \\
\text { GICp/Br/Sol } \\
\text { GICp/Soltrol }\end{array}$ & $\begin{array}{l}0.992 \\
1.007\end{array}$ & $\begin{array}{l}3.007 \\
2.771\end{array}$ & $\begin{array}{l}0.964 \\
0.951\end{array}$ & $\begin{array}{l}0.533 \\
0.624\end{array}$ \\
\hline $\begin{array}{l}\text { GlCp(H)/Brine } \\
\text { GICp(H)/Br/Sol } \\
\text { GICp(H)/Soltrol } \\
\text { GlCp(H)/Sol/Br }\end{array}$ & $\begin{array}{l}0.967 \\
0.941 \\
1.006\end{array}$ & $\begin{array}{l}3.011 \\
2.597 \\
\\
3.103\end{array}$ & $\begin{array}{l}1.003 \\
0.924 \\
0.957\end{array}$ & $\begin{array}{l}0.459 \\
0.518 \\
0.532\end{array}$ \\
\hline $\begin{array}{l}\text { TfCp(H)/Brine } \\
\text { TfCp(H)/Br/Sol } \\
\text { TfCp }(\mathrm{H}) / \mathrm{Solttrol} \\
\mathrm{TfCp}(\mathrm{H}) / \mathrm{Sol} / \mathrm{Br}\end{array}$ & $\begin{array}{l}0.993 \\
1.007 \\
\\
1.006\end{array}$ & $\begin{array}{l}3.122 \\
2.858 \\
\\
3.035\end{array}$ & $\begin{array}{l}0.955 \\
0.951 \\
0.952\end{array}$ & $\begin{array}{l}0.517 \\
0.568 \\
0.532\end{array}$ \\
\hline
\end{tabular}

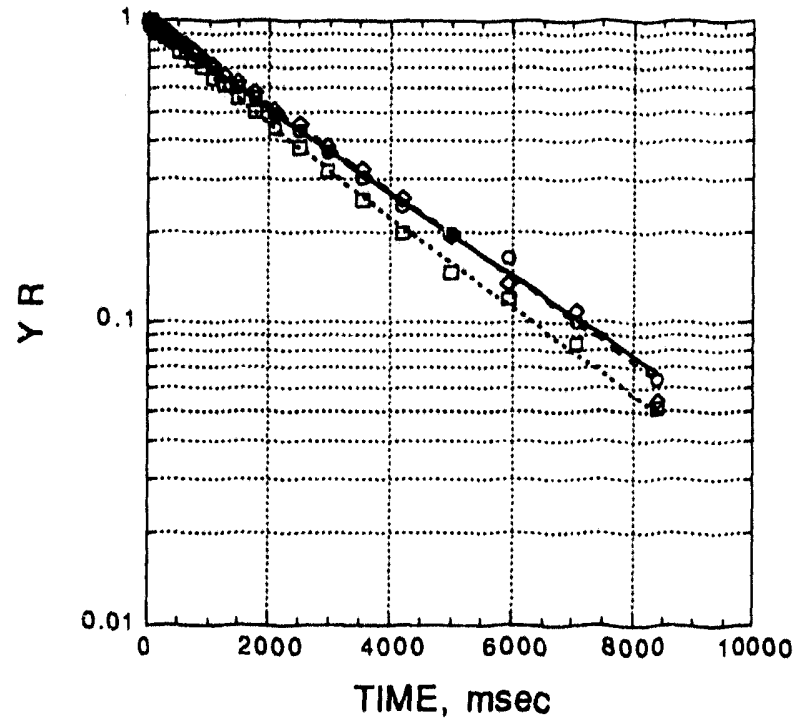

Fig 10 Plot of normalized magnetic moment $Y R(t)$ versus time in milliseconds for horizontally mounted glass capillary bundle; - single-phase brine; $\cdots$-... brine phase in two-phase brine/Soltrol; - - - brine phase in two-phase Soltrol/brine.

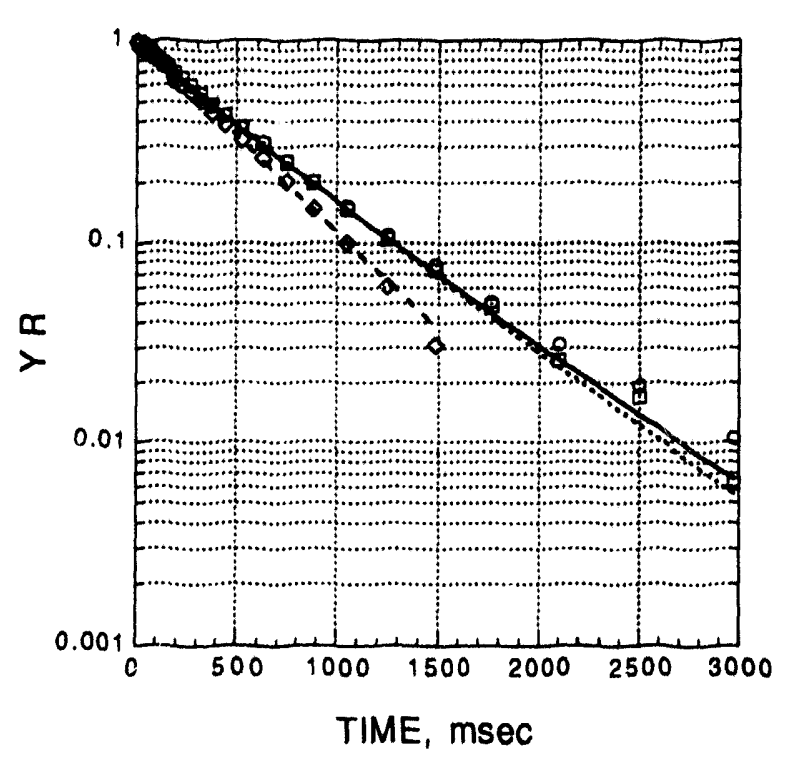

Fig 11 Plot of normalized magnetic moment $Y R(t)$ versus time in milliseconds for horizontally mounted glass capillary bundle; - single-phase Soltrol; ...-... Soltrol phase in two-phase Soltrol/brine; - - - - Soltrol phase in two-phase brine/Soltrol. 


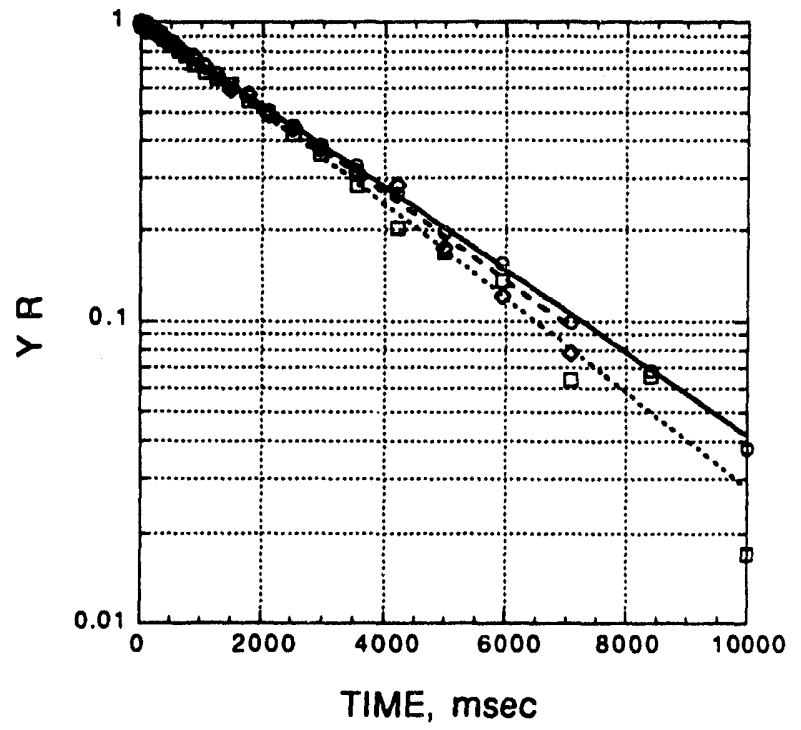

Fig 12 Plot of normalized nagnetic moment $Y R(t)$ versus time in milliseconds for horizontally mounted Teflon capillary bundle; brine phase in two-phase brine/Soltrol; - - - - brine phase in two-phase Soltrol/brine.

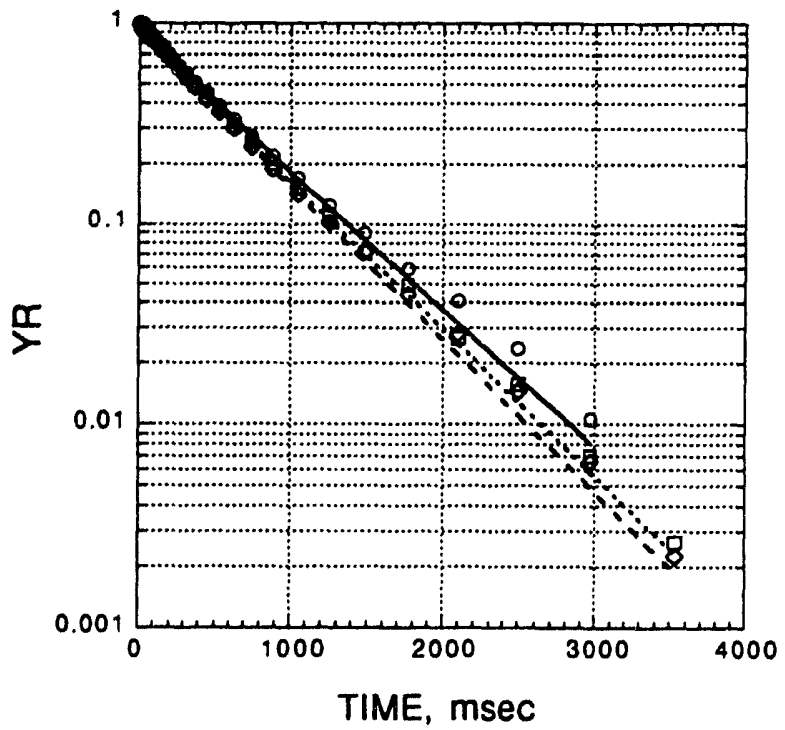

Fig 13 Plot of normalized magnetic moment $Y R(t)$ versus time in milliseconds for horizontally mounted Teflon capillary bundle; phase in two-phase Soltrol/brine; - - - - Soltrol phase in two-phase brine/Soltrol.

inhomogeneity caused by the differences in magnetic susceptibilities between the tube materials and fluids (Glasel and Lee, 1974). With the bundle mounted vertically, the magnetic field being parallel to the tubes does not cross regions of different susceptibility, and local field inhomogeneities are minimized, leading to narrow lines. With the bundle mounted horizontally, the magnetic field crosses regions of different susceptibility, accentuating local field inhomogeneities, and leading to broader lines. The trends in the stretched exponential parameters for the various fluid systems are somewhat ambiguous. The two phases in the brine wetting phase system had the shortest relaxation times while the two phases in the Soltrol wetting system had the longest relaxation times. The second fluid in the two-phase systems had relaxation curves that were essentially linear, but the relaxation time for the brine was the longest while that for the Soltrol as second fluid was the shortest. The relaxation curves for the first fluid, whether in a one- or two-phase system, were significantly nonlinear. Again, the brine and Soltrol behaved oppositely wiin the brine in the one-phase system having the lesser nonlinearity while the Soltrol in the onephase system had the most nonlinearity.

Figures 12 and 13 show the results for the Teflon tube bundles mounted horizontally. The parameters for the stretched exponential fits are given in Table 2 . These results have somewhat different trends compared to those for the other systems. First, the variation in relaxation times for different solveni systems is less pronounced than that for the other two cases. Second, the brine curves were all essentially linear, while the Soltrol curves had essentially the same degree of nonlinearity. Also, the Soltrol parameters for the two-phase systems are similar to those measured for the Soltrol phase in the model core plug phantom.

\section{OBSERVATIONS}

Although the capillary tube bundle phantoms all had fluid systems which revealed nonlinearities and thus implied some distribution in the V/S ratios, their nonlinearity was not as pronounced as that observed for brine in the much more complex native rock systems. Considering that in almost every case the Soltrol curves had more nonlinearity than the brine curves for the phantom data, oil in rock plugs might exhibit greater nonlinearity than observed for the brine data. Every twophase system where brine was the first phase added to the phantom, regardless of whether it was a wetting fluid for the tube material or not, had the shortest relaxation times for both the phases. Why this occurs has not been explained. Other investigators have generally reported only relaxation data for brine in rock or model systems. The behavior of even these relatively simple model systems with two phases has more complexity than that anticipated. Much more study of more realistic model systems is necessary before some of these effects can be adequately explained.

\section{ACKNOWLEDGMENTS}

This work was performed for the U. S. Department of Energy (DOE) under Cooperative Agreement DE-FC2283FE60149. The authors thank Mike Madden of NIPER for his assistance in performing this work. We thank the NIPER personnel who reviewed this manuscript, and Bob Lemmon, the DOE Project Manager, for his support. 


\section{REFERENCES}

Anderson, W. G., 1986. Wettability Literature Survey Part 2: Wettability Measurement. J. Pet. Technol., November, p. 1246.

Barrufet, M. A., R. W. Flumerfelt, M. P. Walsh, and A. T. Watson, 1993. Development of Nuclear Magnetic Resonance Imaging/Spectroscopy for Improved Petroleum Recovery. Publication in progress.

Borgia, G. C., P. Fantazzini, and E. Mesini, 1991. Wettability Effects on Oil-Water-Configurations in Porous Media: A Nuclear Magnetic Resonance Relaxation Study. J. Appl. Phys., 70 (12), p. 7623.

Borgia, G. C., P. Fantazzini, G. Fanti, and E. Mesini, 1992. Magnetic Resonance Relaxation Study of Preferential Wettability Effects on Displacement Efficiency in Chalk Samples. J. Pet. Sci. Eng., 8, p. 153.

Brown, R. J. S. and I. Fatt, 1956. Measurements of Fractional Wettability of Oilfield Rocks by the Nuclear Magnetic Relaxation Method. Trans., AIME, 207, p. 262.

Cuiec, Louis E., 1991. In: Interfacial Phenomena in Petroleum Recovery, (N. R. Morrow, ed.), Marcel Dekker, Inc., New York, pp. 319 - 375.

Doughty, Daryl A., and Nicida L. Maerefat, 1987. Transformation of an NMR Spectrometer into an NMR Imager for Evaluating Fluid Content and Rock Properties of Core Samples. Proc., Society of Core Analysts First Annual Technical Conference, Dallas, Texas, August 19 21.

Doughty, Daryl A., and Nicida L. M!aerefat, 1988. Modifications to a JEOL GX270 Wide bore Spectrometer for Magnetic Resonance Imaging: Petrographic Applications. 29th Experimental Nuclear Magnetic Resonance Spectroscopy Conference, Rochester, New York, April 17-21.

Doughty, Daryl A., and Nicida L. Maerefat, 1989. Preliminary Transformation of an NMR Spectrometer into ar NMR Imager for Evaluating Fluid Content and Rock Properties of Core Samples. The Log Analyst, MarchApril, p. 78.

Doughty, Daryl A. and Liviu Tomutsa. NMR Microscopy for Fluid Imaging at Pore Scale in Reservoir Rock. Joint Society of Core Analysts/Society of Professional Well Log Analysts Symposium, Oklahoma City, Oklahoma, June 14-17, 1992.
Doughty, Daryl A., Liviu Tomutsa, and Michael P. Madden, 1992. Pore Scale Fluid Imaging in Reservoir Rock by NMR Microscopy. Symposium on Applications of Magnetic Resonance Imaging in Enhanced Oil Recovery, Division of Geochemistry, ACS National Spring Meeting, Denver, Colorado, March 28 - April 2.

Glasel, J. A. and K. H. Lee, 1974. On the Interpretation of Water Nuclear Magnetic Resonance Relaxation Times in Heterogeneous Systems. J. Am. Chem. Soc., 96 (4), p. 970.

Kenyon, W. E., P. I. Day, C. Straley, and J. F. Willemsen, 1988. A Three-Part Study of NMR Longitudinal Relaxation Properties of Water-Saturated Sandstones. Soc. Pet. Eng. Form. Eval., 3, p. 622.

Kumar, J., I. Fatt, and D. N. Saraf, 1969. Nuclear Magnetic Relaxation Time of Water in a Porous Medium with Heterogeneous Surface Wettability. J. Appl. Phys., $40(10)$, p. 4165.

Mahmood, Syed M., Daryl A. Doughty, Liviu Tomutsa, and Matt Honapour, 1990. Pore Level Fluid Imaging Using High Resolution Nuclear Magnetic Resonance Imaging and Thin Slab Micromodels, Proc. Society of Core Analysts Fourth Annual Technical Conference, Dallas, Texas, August 13-15.

Roussel, J. C., C. Chardaire-Riviere, and M. Robin, 1992. In: Physical Chemistry of Colloids and Interfaces in Oil Production, (H. Toulhoat and J. Lecourtier, ed.), Editions Technip, Paris, 1992, pp. 165-166.

Tomutsa, Liviu, Daryl A. Doughty, and Alan Brinkmeyer, 1992. Integration of Computed Tomography, Nuclear Magnetic Resonance Microscopy, Computer Assisted Petrographic Image Analysis and Flow Simulation for Heterogeneous Core Characterization. Society of Petroleum Engineers Forum Series in North America, Frontiers in Technology, Special Core Analysis and Applications to Reservoir Engineering. Snowmass Village, Colorado, July 12-17. 

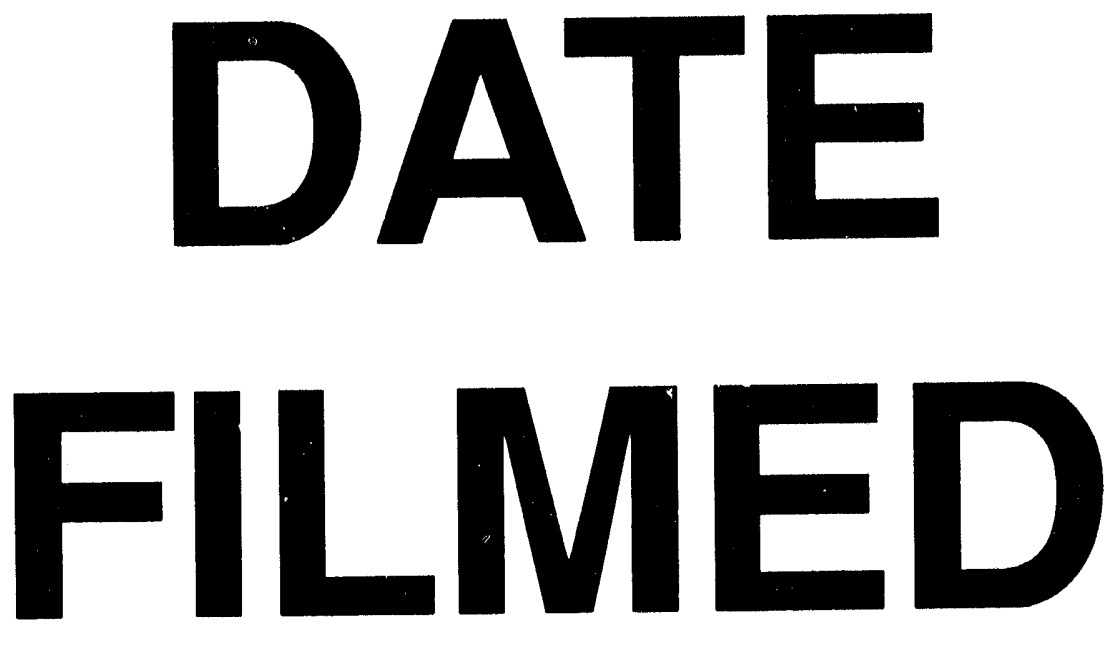

$6 / 2 / 94$
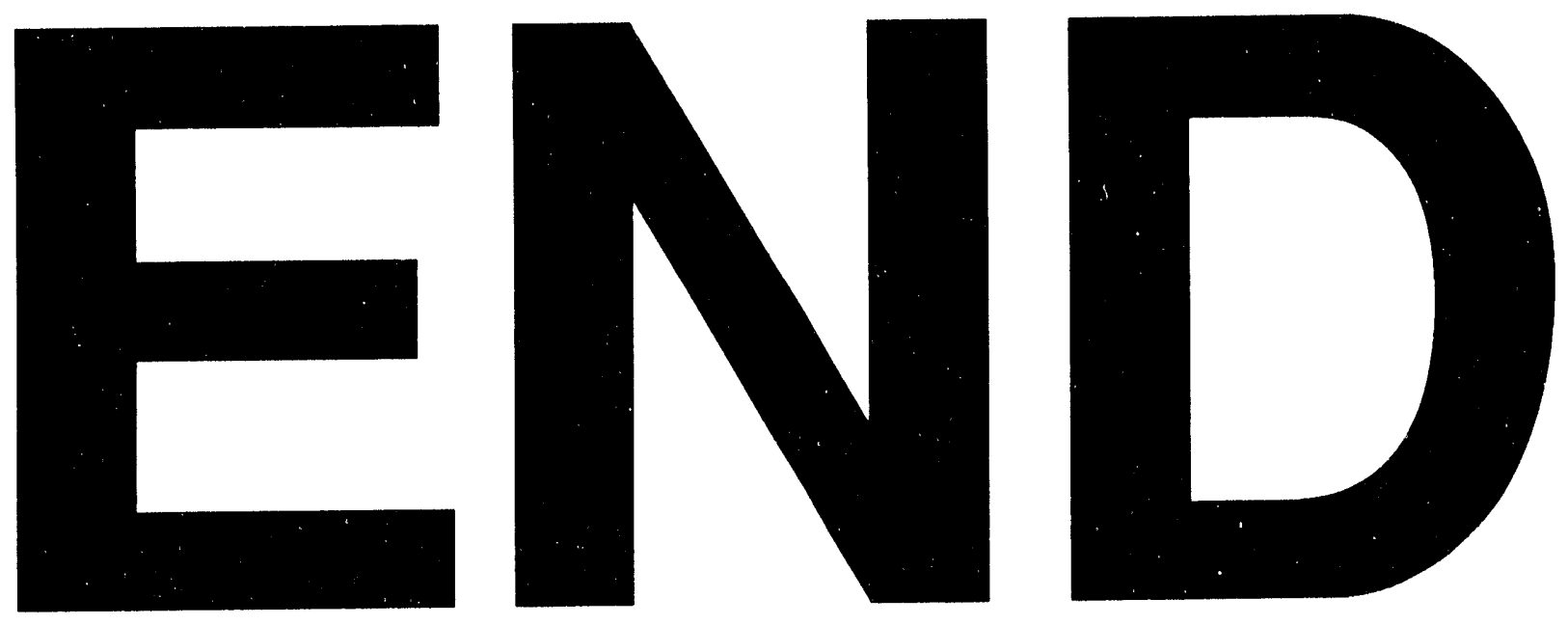


$$
\text { (10) }
$$

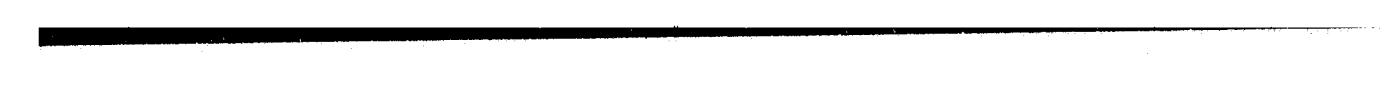

